\title{
33. Using EVALUATE (2)
}

An alternative way to use the EVALUATE statement is as follows:

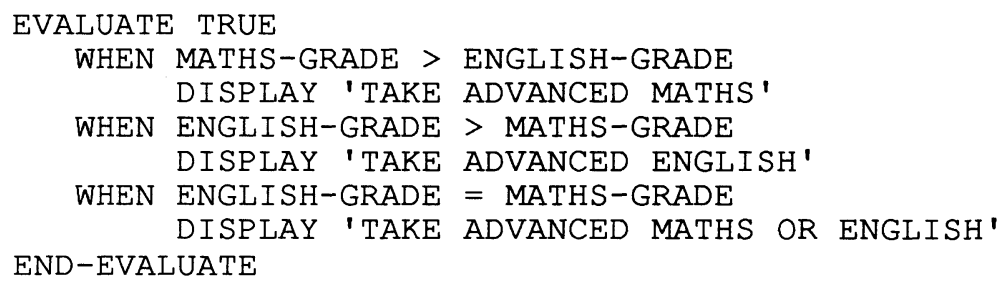

In this case EVALUATE - instead of being followed by the name of a data item is followed by the word TRUE.

This means that the computer will check to see which condition is true - then carry out the statement which follows it.

Note that in the example above WHEN OTHER could be used instead of WHEN ENGLISH-GRADE = MATHS-GRADE - but the latter is probably clearer.

\section{Exercises}

Using EVALUATE

1. Repeat the exercises from the previous lesson using EVALUATE TRUE.

2. Write a program which will ask an employee for his/her length of service. The program should then display a bonus as follows:

Staff with more than 5 years' service get $£ 2000$

Staff with more than 3 years' service get $£ 1000$

Staff with more than 1 years' service get $£ 300$

Other staff get $£ 100$.

3. Write a program which will ask for the names and lengths of service for two members of staff. The program should display the name of the employee who has the longer service followed by the message 'is promoted to manager'. If their time with the company is the same - then the message 'No promotions' should be displayed. 